\title{
Long QT syndrome with torsade in a patient with atrial fibrillation taking antihistamines- Case report
}

\author{
Mariana Oliveira Marasca ${ }^{1}$, Almir Alamino Lacalle ${ }^{1}$, Giovana Saliba de Paula ${ }^{1}$, Bárbara Dias de Souza ${ }^{1}$, Alexia Campos Baldi ${ }^{1}$, Juan Carlos Yugar-Toledo, \\ $\mathrm{MD}, \mathrm{PhD}^{2}$, Elizabeth do Espirito Santo Cestário, $\mathrm{MD}^{2,3}$
}

\begin{abstract}
Maracsa MO, Lacalle AA, De Paula GS, et al. Long QT syndrome with torsade in a patient with atrial fibrillation taking antihistamines- Case report. Curr Res Cardiol. 2017;4(3):48-51.

OBJECTIVE: To report the case of a patient with long QT syndrome acquired after treatment of atrial fibrillation associated with the regular use of antihistamines.
\end{abstract}

METHODS: The data of this work were obtained by reviewing medical records, the diagnostic tests to which the patient was submitted, and a literature review.
FINAL CONSIDERATIONS: The reported case and published studies bring to light a discussion on long QT syndrome acquired consequent to the association of antiarrhythmic and antihistaminic drugs. An apparently innocuous association, however, different mechanisms of action on cardiac ion channels overlap, predisposing patients to acquire long QT syndrome and its feared complications.

Key Words: Acquired long QT syndrome; Torsade de pointes; Atrial fibrillation; Antihistamines
I ong QT syndrome (LQTS) is a disease characterized by a prolonged QT $\mathcal{L}_{\text {interval. The etiology of this syndrome, which causes alterations to the }}$ ionic channels of cardiac cells, can be genetic or acquired. Defects that alter the flow of sodium, potassium, or calcium during the action potential extend the QT interval. These changes predispose patients with this syndrome to malignant ventricular arrhythmias (1).

The onset of ventricular arrhythmias seems to be due to early postdepolarizations, which occur when there is prolongation of the plateau phase of the action potential as a consequence of an accumulation of intracellular calcium. Variations in myocardial repolarization, indicated by a longer QT interval, predispose subjects to polymorphic ventricular arrhythmias in response to a trigger. The typical arrhythmia of this syndrome is Torsade de Pointes (TdP), a polymorphic ventricular tachycardia, in which the QRS complex twists around the isoelectric baseline of the electrocardiogram (2).

LQTS can manifest clinically with episodes of syncope, often resulting in cardiorespiratory arrest and sudden death. These syncopal episodes result from ventricular tachycardias, in particular TdP. On the electrocardiogram, LQTS can be demonstrated when the QT interval is greater than 0.66 seconds; this interval should be corrected according to the heart rate using the Bazett formula $(\mathrm{QTC}=\mathrm{QT} / \sqrt{\mathrm{RR}})(3)$.

A prolonged QT interval may be triggered by electrolyte disturbances (hypokalemia, hypomagnesaemia and hypokalemia), central nervous system injury such as stroke, encephalitis, and drugs. Amiodarone, chloroquine, chlorpromazine, clarithromycin, droperidol, erythromycin, gatifloxacin, haloperidol, penatmidine, procainamide, quinidine and sotalol are among the drugs associated with this condition (4).

\section{OBJECTIVE}

To report the case of a patient with acquired long QT syndrome that developed after the treatment of atrial fibrillation associated with the regular use of antihistamines.

\section{CASE REPORT}

\section{Patient workup}

A 73-year-old male patient sought emergency care complaining of intense dyspnea, orthopnea, and nocturnal paroxysmal dyspnea with progressive worsening. The condition had deteriorated in the week prior to his consultation with lower limb edema and abdominal distension.
This patient had been evaluated about 40 days before and there was no sign of heart failure or arrhythmia. the echocardiogram performed routinely in this period had normal EF and no change in relaxation. Left atrial volume was normal. The ECG was in sinus rhythm, with normal QT interval (Figure 1).

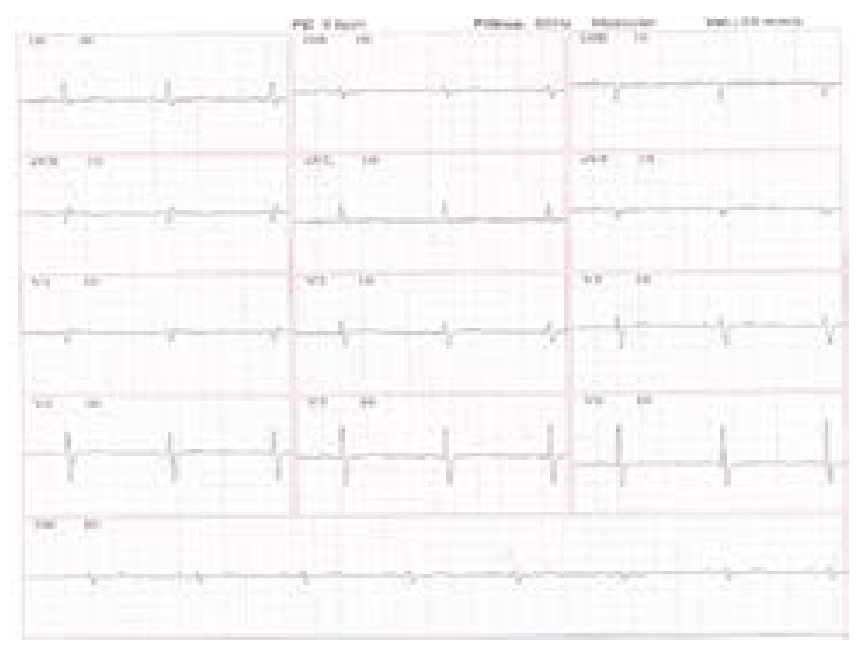

Figure 1) Prior ECG

The patient reported having been hospitalized for about one-month due to pneumonia, and had been taking warfarin for the previous four weeks because of atrial fibrillation diagnosed during the hospitalization. According to the patient, electrical cardioversion was planned to reverse the arrhythmia. During the hospitalization, biochemical tests were performed, which did not diagnose disorders of potassium, calcium or magnesium (Table 1).

In addition, the patient performed an echocardiogram that identified a normal ejection fraction, without areas of segmental dysfunction. Left atrial volume remained normal.

Regarding the patient's history, he reported systemic arterial hypertension, dyslipidemia, bronchial asthma, allergic rhinitis and a previous stroke. $\mathrm{He}$ was taking amiodarone, rivaroxaban, rosuvastatin, phenytoin, venlafaxine,

\footnotetext{
${ }^{1}$ Medical Students-University Center of Votuporanga, Unifev-São Paulo, Brazil, ${ }^{2}$ Department of Internal Medicine, Hypertension Clinic, State Medical School of São José do Rio Preto (FAMERP), São Paulo, Brazil, 3Professor of the Medicine Course-University Center of Votuporanga - Unifev - São Paulo. Brazil

Correspondence: Dr Elizabeth do Espirito Santo Cestário, MD, Department of Internal Medicine, Hypertension Clinic, State Medical School of São José do Rio Preto (FAMERP), São Paulo, Brazil, Telephone+55 (17) 3405-9999, e-mail cestario@cardiol.br/escestario@gmail.com

Received: August 12, 2017, Accepted: September 05, 2017, Published: September 07, 2017 
TABLE 1

\section{Prior laboratory tests}

\begin{tabular}{cc}
\hline Prior Test & Values \\
\hline Sodium & 142 \\
Potassium & 4.5 \\
Magnesium & 2,1 \\
lonic calcium & 4,69 \\
Total calcium & 9,2 \\
Urea & 25 \\
Creatinine & 1 \\
Glycemia & 100 \\
Ht/ Hb & $42 / 14.2$ \\
Leukocytes & 5.2 \\
Band neutrophils & 0 \\
Segmented & 63 \\
Platelets & 280 \\
\hline
\end{tabular}

esomeprazole and celergin ${ }^{\circledR}$ (dexchlorpheniramine maleate with betamethasone), but the attending physician did not know that the patient made continuous use of antihistamines.

\section{Physical examination}

The patient was underweighting with pallor. His heart rate was $100 \mathrm{bpm}$, respiratory rate was $30 \mathrm{ipm}$ and his arterial pressure was $120 / 72 \mathrm{mmHg}$. Pulmonary auscultation identified vesicular murmur audible in all lung fields, but reduced at the bases, and the presence of bilateral crepitations. Heart auscultation identified an irregular rhythm, presence of systolic murmur at the left sternal border and mitral focus.

His abdomen was painful on upper palpation; the liver was smooth, palpable at about $5 \mathrm{~cm}$ from the right costal border. Carotid pulses were preserved and symmetrical. Both extremities were swollen $(3+/ 4+)$. The neurological evaluation was without alterations.

\section{Diagnostic hypothesis}

A diagnostic hypothesis of decompensated heart failure with atrial fibrillation was reached.

\section{Conduct}

The patient received initial treatment for heart failure, and was submitted to several biochemical and imaging tests.

The patient's electrocardiogram (ECG) with controlled heart rate atrial fibrillation is shown in Figure 2.

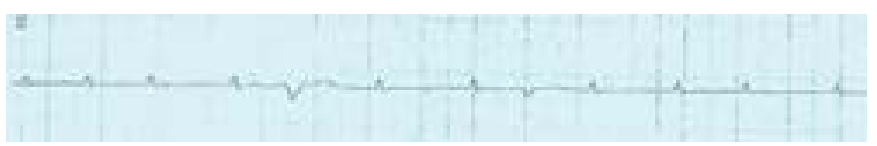

Figure 2) DII derivation showing atrial fibrillation

The echocardiogram identified significant left ventricular systolic dysfunction with an ejection fraction of $28 \%$.

High D-dimer was found by laboratory tests and chest tomography was requested to investigate pulmonary thromboembolism, but the examination demonstrated a significant increase in the cardiac area, associated with pleural and pericardial effusion but without evidence of embolism.

As the patient did not improve with the established therapy, he was transferred to the intensive care unit.

\section{Evolution in the intensive care unit}

After the initial evaluation and within 30 days of oral anticoagulant use, the medical team opted for electrical cardioversion to improve the hemodynamic conditions of the patient. The ECG after electrical cardioversion shown in Figure 3.

About one hour after electrical cardioversion, the patient had recurrent episodes of syncope with wide QRS tachycardia but he responded promptly to electrical cardioversion with complete recovery of consciousness. The electrolytes were controlled and there were no gastric disorders. The evolution of laboratory tests is shown in Table 2 .

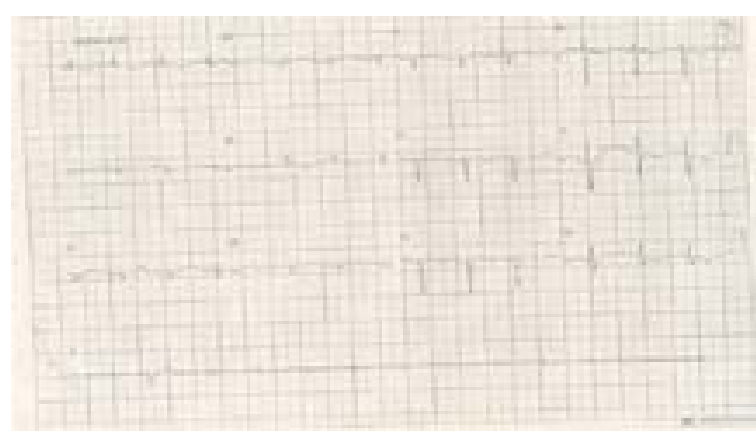

Figure 3) ECG after electrical cardioversion

TABLE 2

\section{Laboratory tests}

\begin{tabular}{cccccc}
\hline Test & $1^{\text {st }}$ day & $2^{\text {nd }}$ day & $4^{\text {th }}$ day & $6^{\text {th }}$ day & $8^{\text {th }}$ day \\
\hline Sodium & 137 & 136 & 136 & 137 & 151 \\
Potassium & 4.2 & 4.4 & 3.2 & 3.8 & 2.2 \\
Magnesium & - & 2.05 & - & 2.24 & 2.19 \\
lonic calcium & - & - & 3.25 & - & - \\
Total calcium & - & - & 7.49 & - & 8.5 \\
Urea & - & 27.3 & - & 35.1 & 38.1 \\
Creatinine & 1.03 & 0.87 & - & 0.66 & 0.74 \\
Clearance & - & 42.95 & - & - & - \\
Glycemia & 107 & 122 & 90 & 87 & - \\
Ht/ Hb & $36.6 / 12.3$ & $41 / 13.7$ & $43.1 / 14.4$ & $39.1 / 13.6$ & $41 / 13.5$ \\
Leukocytes & 6.8 & 6.9 & 11.7 & 8.6 & 8.3 \\
Band neutrophils & 2.2 & 2.2 & 3.2 & 6.7 & 4.2 \\
Segmented & 64.7 & 52.8 & 57.2 & 70.9 & 59.7 \\
Platelets & 283 & 291 & 182 & 233 & 205
\end{tabular}

PCR 18.3

Lactate 9.7

INR 1.52

A continuous infusion of amiodarone was started, but the patient still presented episodes of syncope and tachycardia. Because of the difficulty in controlling his arrhythmia, a 24-hour ECG Holter was used. The report showed sinus rhythm conducted with a wide QRS complex and a QT interval increased to up to 676 milliseconds (Figure 4).

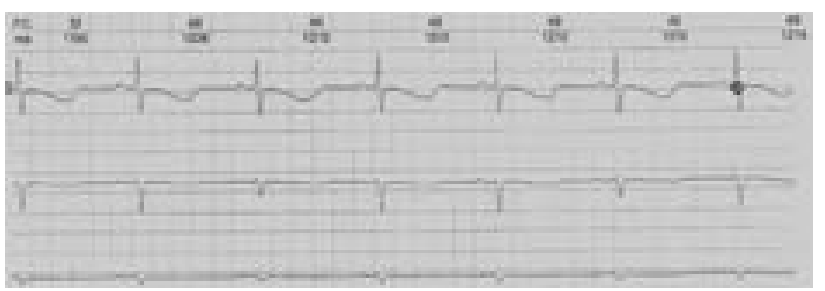

Figure 4) 24-hour ECG Holter showing sinus rhythm with a wide QRS complex and a QT interval of up to 676 milliseconds

The patient suffered frequent extrasystoles and polymorphic ventricular torsectomies (torsade de pointes), sometimes sustained and requiring electrical cardioversion; the longest episode lasted 1 minute and 35 seconds with a heart rate of 155 beats per minute, demonstrating a severe arrhythmia, torsade de Pointes (Figures 5 and 6).

In view of his condition, a transvenous pacemaker was used with an elevated heart rate (overdrive suppression) and intravenous magnesium sulphate was administered. This procedure had a satisfactory response with cessation of the arrhythmia and the patient was referred after a few days for the implantation of a defibrillator pacemaker because the patient had stable episodes of polymorphic extrasystoles and non-sustained ventricular tachycardia after 


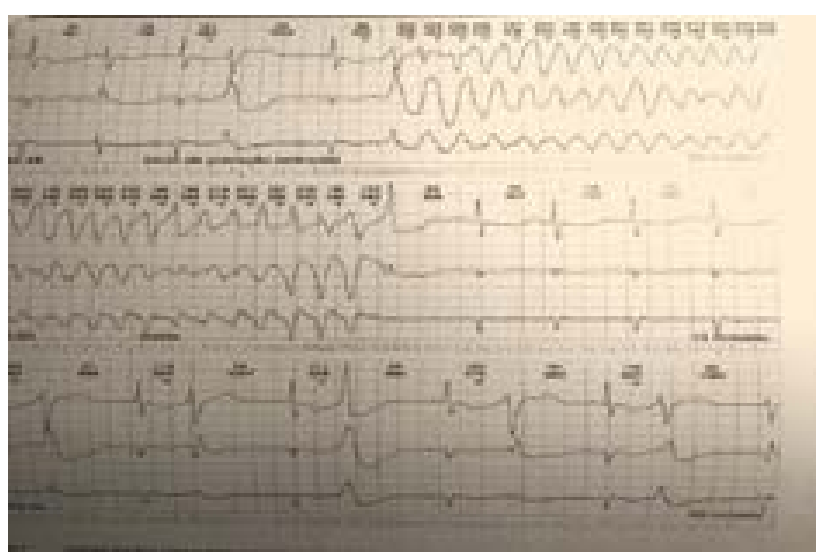

Figure 5) 24-hour ECG holter

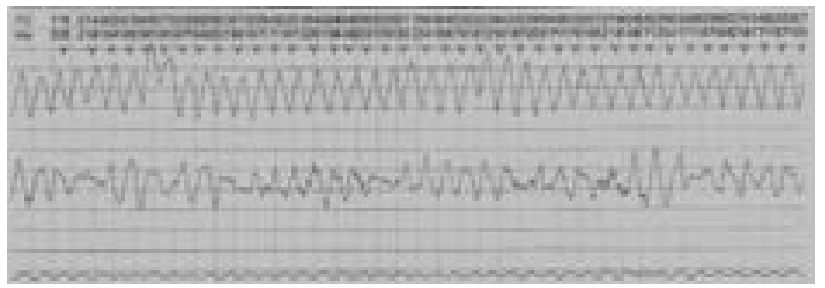

Figure 6) 24-hour ECG holter

the stabilization of the condition. On the days that followed, the patient presented worsening of his pulmonary condition and required antibiotics.

\section{Complementary examinations}

Chest X-ray: Interstitial infiltrate in the pulmonary bases, opacity along the left costophrenic sinus suggestive of pleural reaction with evaluation of the cardiac area being impaired.

Cardiac catheterization: Coronary arteries free of lesions. Severe left ventricular dysfunction. During catheterization, the patient had another syncope with tachycardia and received electrical cardioversion.

Laboratory tests: The complete blood count showed mild anemia with a hematocrit of $36.60 \%$ and hemoglobin of $12.3 \mathrm{~g} / \mathrm{dL}$. The values of mean corpuscular volume, mean corpuscular hemoglobin and mean corpuscular hemoglobin concentration were within the limits of normality, leukocytes were $6.8 \times 10^{3} / \mu \mathrm{L}$ without left shift and platelet count was $283 \times 10^{9} / \mathrm{L}$. Renal function and electrolytes were within normal ranges (Table 2).

Venous doppler of lower limbs: No signs of deep venous thrombosis.

Chest angiotomography: No signs of pulmonary embolism.

\section{Evolution and follow-up}

The patient had a stable arrhythmia, but he developed nosocomial pneumonia, sepsis, multiple organ failure and death after about 50 days.

\section{DISCUSSION}

Long QT syndrome, characterized by a prolonged QT interval, has a genetic or acquired etiology. Patients are predisposed to malignant ventricular arrhythmias, which can lead to syncope, cardiorespiratory arrest and sudden death. The typical arrhythmia of this syndrome is torsade de pointes (TdP), a polymorphic ventricular tachycardia, in which the QRS complex twists around the isoelectric baseline of the electrocardiogram (5).

A QT interval of more than 0.66 seconds can be identified on the electrocardiogram. The QT interval is measured from the beginning of the QRS complex until the end of the $T$ wave, and its measurement must be corrected according to the heart rate using the Bazett formula $(\mathrm{QT}=\mathrm{QT} / \sqrt{\mathrm{RR}})$ (3). The QT interval of the majority of patients with long QT syndrome corrected by this formula are between 4 and 460 milliseconds in men and 4 to 480 milliseconds in women (6).

Prolongation of the QT interval in the acquired form of the condition can be triggered by electrolytic disturbances, such as hypokalemia, hypomagnesaemia and hypokalemia, central nervous system injuries, such as in cases of stroke and encephalitis, and use of antiarrhythmic drugs, such as amiodarone, antibiotics such as clarithromycin and antihistamines such as diphenhydramine and dexchlorpheniramine (4).
Amiodarone, a widely used antiarrhythmic drug, is one of the main drugs with the potential to cause long QT syndrome. Several studies show the association of this drug with others is the trigger of this syndrome (7-9). Its pharmacodynamics consist of blocking cardiac potassium channels, increasing the duration of the action potential and reducing normal automatism. However, this drug may disproportionally prolong cardiac action potentials, especially when the underlying heart rate is slow (10).

Although undesirable effects are identified with antiarrhythmic drugs, which end up prolonging the QT interval, these effects may also occur using drugs with non-cardiac indications such as antihistamines and antibiotics. Moreover, the association of these drugs may potentiate QT prolongation and may predispose the patient to malignant ventricular arrhythmias (10).

Antihistamines also affect contractility and electrical conduction of the heart. The stimulation of histamine in its respective cardiac receptors (H1 and H2) causes an increase in the contractile force of the atrial and ventricular muscles, as it facilitates the entry of calcium and accelerates the heart rate, thereby shortening the diastolic depolarization in the sinus node. Therefore, the use of antihistamines such as dexchlorpheniramine, one of the most potent $\mathrm{H} 1$ receptor antagonists, impedes the influx of calcium in cardiac cells and delays diastolic depolarization in the sinus node, also causing prolongation of the QT interval (10).

The patient of this report had acquired long QT syndrome and with its most feared manifestation, torsade de pointes. As the etiological agent of this arrhythmia, we identified two main factors, the chronic use of dexchlorpheniramine associated with the recent use of amiodarone due to atrial fibrillation. At the time the torsade condition started, there were no electrolytic disturbances that could be implicated as the cause, although in the course of the days after the first event, the patient had hypokalemia and hypocalcemia (Table 2). Progressive hypokalemia presented by the patient is probably secondary to the use of diuretics for heart failure.

\section{CONCLUSION AND FINAL CONSIDERATIONS}

The case reported and the literature review bring to light the discussion of acquired long QT syndrome as a consequence of the combination of antiarrhythmic drugs (amiodarone) and antihistamines (dexchlorpheniramine and betamethasone). Antihistamines drugs caused LQT and torsade de pointes is not a new conception, but although it is not well remembered in daily practice. An apparently innocuous association, however, their different mechanisms of action on cardiac ion channels overlap, predisposing patients to acquired long QT syndrome and its feared complications.

Our intention with this work is to draw attention to this important drug interaction, so that other colleagues can be alerted to the complications of these interactions.

\section{ACKNOWLEDGEMENTS}

The authors acknowledge the subject, his parent, other healthcare practitioners who participated in his care.

\section{DISCLOSURES}

None

\section{ETHICAL DISCLOSURES}

Informed and written consent were obtained from the parent of this reported case. The necessary institutional protocols on the publication of the data were duly followed.

\section{FUNDING}

This case report did not receive financial support.

\section{CONFLICT OF INTEREST}

No conflict of interest among the authors.

\section{REFERENCES}

1. Souto M, Kass RS. Ionic potassium channels associated with long acquired QT syndrome. Rev Bras Cardiol. 2011;24(1):42-51.

2. Fauci AS, Kasper DL, Hauser SL, et al. Medicina Interna de Harrison. (18th ed) Porto Alegre: AMGH. 2013.

3. Nogueira RGB, Rebello ES, Rebello APS, et al. Síndrome do QT longo. Estud Biol. 2010/2011;32/33(76-81):105-10. 
4. Oliveira Jr NA, Andréa EM, Maciel WA, et al. Eletrocardiograma e a Síndrome de QT longo. Rev Socerj. 2004;17(3):177-82.

5. Pereira MD, Orzi M, Rozas A, et al. Síndrome do QT longo. Femina. 2006;34(7):493-7.

6. Lemos LFM. Medicamentos com potencial para prolongar o intervalo QT e precauç̃es a ter na prática clínica com a sua utilizaç̃o: Experiência Profissionalizante na Vertente de Farmácia Comunitária e Investigação. Covilhã. Tese (Mestrado em Ciências Farmacêuticas). Universidade Beira do Interior, Portugal. 2013.

7. Huemer M, Sarganas G, Bronder E, et al. Torsade de pointes tachycardia in a patient on dronedarone therapy. Pharmacotherapy. 2015;35:e61-5.
8. Bienias P, Ciurzyński M, Paczyńska M, et al. Cardiac arrest and electrical storm due to recurrent torsades de pointes caused by concomitant clarithromycin, cotrimoxazole and amiodarone treatment. Pol Merkur Lekarski. 2014;37(221):285-8.

9. Tarapués M, Cereza G, Arellano AL, et al. Serious QT interval prolongation with ranolazine and amiodarone. Int $\mathrm{J}$ Cardiol. 2014;172(1):e60-1.

10. Brunton LL, Chabner BA, Knollmann BC. As bases Farmacológicas da Terapêutica de Goodman and Gilman. (12th ed) Porto Alegre: AMGH. 2012. 